\title{
Thermodynamic Stability of Clusters of Molybdenum Oxide
}

\author{
Ivana Lj. Validzic, Gijs van Hooijdonk, Stefan Oosterhout, and Willem K. Kegel* \\ Van't H off Laboratory for Physical and Colloid Chemistry, Debye Research Institute, \\ Utrecht University, Padualaan 8, $3584 \mathrm{CH}$ Utrecht, The Netherlands
}

Received October 24, 2003. In Final Form: December 19, 2003

\begin{abstract}
We show that a single geometrical rule underlies the stability of "polyoxomolybdates", the variety of clusters of molybdenum(VI) oxidein (acidified) aqueous solution that arefound experimentally. We predict that upon increasing the proton or total molybdenum oxide concentration, the average size of the clusters increases. We compare our predictions with results from ultracentrifugation experiments and with data in the literature. Finally, it is shown that the formation of metal oxide clusters is thermodynamically equivalent to the formation of surfactant micelles.
\end{abstract}

\section{Introduction}

Metal oxides such as molybdenum, tungsten, vanadium, and aluminum oxide in acidified aqueous solutions spontaneously and reversibly form clusters that may contain up to 36 metal atoms. We limit ourselves to molybdenum oxides in this work, but the gl obal behavior we predict is expected to apply to other metal oxides as well. Complexes reversibly form by consuming protons, which, following ref 1 , can be written as the equilibrium

$$
\mathrm{pH}^{+}+\mathrm{qMoO}_{4}^{2-} \rightleftarrows\left[\mathrm{H}_{\mathrm{p}-2 \mathrm{r}} \mathrm{Mo}_{\mathrm{q}} \mathrm{O}_{4 \mathrm{q}-\mathrm{r}}\right]^{(2 \mathrm{q}-\mathrm{p})-}+\mathrm{rH}_{2} \mathrm{O}
$$

In theaboveequilibrium, the cluster $\left[\mathrm{H}_{\mathrm{p}-2 \mathrm{r}} \mathrm{Mo}_{\mathrm{q}} \mathrm{O}_{4 q-r}\right]^{(2 q-p)-}$ is characterized by the combination $(p, q)$ : the numbers of protons and molybdenum monomers that are required to form a cluster, respectively. The value of $r$ quantifies how many protons stick in the cluster; if no protonation occurs, it equals $\mathrm{p} / 2$. Most authors ${ }^{2}$ agree that in the molybdenum(VI) oxide systems, clusters of sizes $q=7$ $((p, q)=(8,7),(9,7),(10,7)$, or $(11,7)$, depending on the degree of protonation) and $8((p, q)=(12,8)$ or $(13,8))$, and 36 (only $(p, q)=64,36)$ ) exist: not only are these species present as ions in solution, but they also form crystals. The structures of these clusters are schematically shown in Figure 1. It can be seen in this figure that clusters mainly consist of octahedrally shaped monomers that are linked at their vertexes. These links are (reversible) chemical bonds: the vertexes linked in the clusters sharean oxygen atom. However, besides octahedral coordination, the $q=$ 36 cluster also contains pentagonal-bipyrimidal units wherethecentral Moion is 7-fold coordinated. Bonds form between two metal oxide monomers when two protons combinewith an oxygen atom at a vertex to produce water; see the above reaction and eq 1 .

Strong evidencefor the existence of thespecies depicted in Figure 1 has been obtained by comparing Raman or $X$-ray spectra of thesolutions tothose of thecrystals. Other clusters, such as $q=12$ (with $(p, q)=(14,12),(15,12)$, or $(16,12)$ ) and $q=18($ with $(p, q)=32,18)$ ), are proposed,

* To whom correspondence should be addressed. E-mail: w.k.kegel@chem.uu.nl.

(1) Tytko, K.-H.; Glemser, O. Adv. Inorg. Chem. Radiochem. 1976, 19, 239

(2) Tytko, K. H. Gmelin Handbook of I norganic Chemistry: Molybdenum, 8th ed.; Springer; Berlin, 1987; Vol. B Зa.
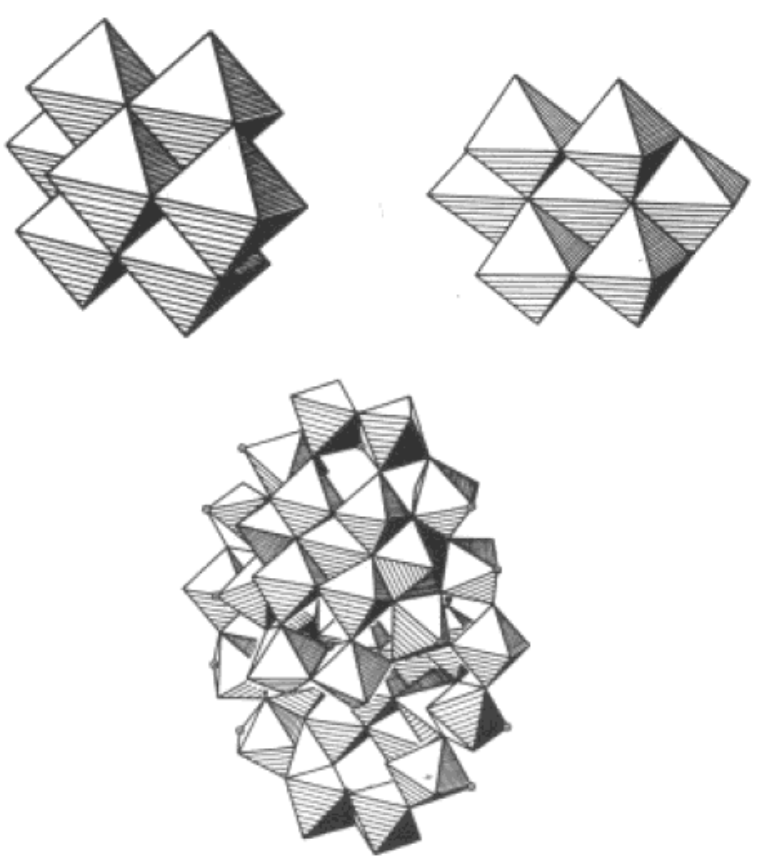

Figure 1. Experimentally observed molybdenum oxide clusters, $\mathrm{Mo}_{7} \mathrm{O}_{24}$ (up left), $\mathrm{MO}_{8} \mathrm{O}_{26}$ (up, right), and $\mathrm{MO}_{36} \mathrm{O}_{108}$ (down, middle); from ref 2 . The clusters mainly consist of octahedrally shaped monomers in which the metal is located in the center of theoctahedra. However, theM 036 cluster al so contains 7-fold coordinated units; see the text. The vertexes of the octahedra are oxygen atoms or (valence) electron pairs. Bonds between the monomers are localized at the vertexes of the metal oxide monomers: shared vertexes indicate bonds. Reprinted with permission from ref 2; copyright Springer 1987.

based on "residual differences" in potentiometric data. These Keggin type structures are expected if other ions (than Mo) are incorporated in the cluster. In tungsten oxide, it has been shown that protons appear to play the role of the central ion; see, for example, ref 1 . Combination of experimental results lead to many "reaction models" in the literature. ${ }^{2}$ These reaction models predict what the concentrations of clusters $(p, q)$ are as a function of $\mathrm{pH}$ and total metal oxide concentration. Predictions of the most successful reaction model in terms of its ability to describe experimental data (model G* in ref 2) are shown in Figure 2. 


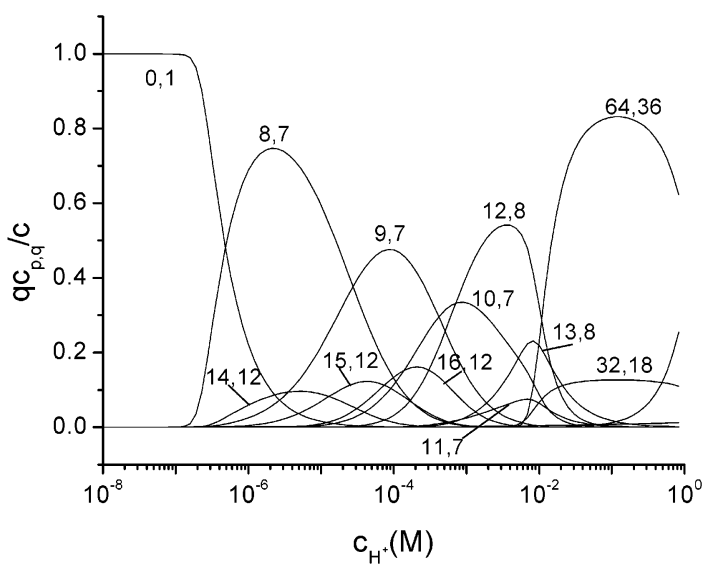

Figure 2. Fraction of species $(p, q)$ as a function of proton concentration according to one of the many reaction models as summarized in ref 2: model G*. The identities of the species $(p, q)$ (see the text) are indicated in the figures. The total molybdate concentration is $0.1 \mathrm{M}$.

It can be seen in Figure 2 that at relatively low proton concentrations only monomers exist, but on increasing $\mathrm{CH}^{+}$, clusters with $\mathrm{q}=7$ appear. These clusters disappear at the expense of even larger clusters when the proton concentration keeps increasing, and ultimately thelargest polyoxomolybdateion of $q=36$ is formed. Increasing the total Mo concentration at constant $\mathrm{CH}_{\mathrm{H}^{+}}$follows the same sequence. At very low molybdate concentrations and very high proton concentrations, however, small, protonated species such as $(p, q)=(2,1)$ and $(5,2)$ appear. Note that for the clusters containing 8 and 12 molybdenum atoms (i.e., $q=8$ and $q=12$ ), the "trend" that clusters become larger upon increasing proton concentration seems reversed. We will get back to this later. The many reaction models in the literature share the property that at rel atively large molybdate concentrations (say $>0.01 \mathrm{M}$ ), globally, larger clusters are encountered upon increasing proton concentration. The fractions of these clusters have maxima as a function of proton concentration. In this work, we seek to explain these properties by a gl obal model, to be confirmed using equilibrium ultracentrifugation measurements.

\section{Empirical Model for the Stability of Metal Oxide Clusters}

Multichemical Equilibrium. The (reversible) clustering of molybdenum oxidecan gl obally bewritten as the chemical equilibrium

$$
\mathrm{pH}^{+}+\mathrm{qMoO}_{4}{ }^{2-} \rightleftarrows \mathrm{Mo}_{\mathrm{q}} \mathrm{O}_{4 \mathrm{q}-\mathrm{p} / 2}+\mathrm{p} / 2 \mathrm{H}_{2} \mathrm{O}
$$

where we neglect species that are protonated. These may in principle be included in our treatment. However, as stated in thel ntroduction, at this stagewelimit oursel ves to understanding the global behavior of the system. Thermodynamic equilibrium implies that $\sum_{\mathrm{i}} v_{\mathrm{i}} \mu_{\mathrm{i}}=0$, where $v_{\mathrm{i}}$ and $\mu_{\mathrm{i}}$ are the stoichiometric coefficients and the chemical potentials of the components $i$, respectively. Writing, for $\mathrm{i}=\mathrm{H}^{+}, \mathrm{MoO}_{4}{ }^{2-}$, and $\mathrm{Mo}_{q} \mathrm{O}_{4 q-\mathrm{p} / 2}$, the chemical potential as $\mu_{\mathrm{i}} \approx \mu_{\mathrm{i}}^{0}+\mathrm{kT}$ In $\mathrm{c}_{\mathrm{i}}$ where $\mu_{\mathrm{i}}^{0}$ is the standard chemical potential and $c_{i}$ is the concentration of component i relative to the "standard concentration" $\mathrm{c}^{0}=1 \mathrm{M}$, we get

$$
\mathrm{c}_{\mathrm{q}}=\mathrm{K} \mathrm{c}_{\mathrm{H}+}^{\mathrm{p}} \mathrm{c}_{1}^{\mathrm{q}}
$$

with

$$
K=\exp \left(\frac{q u_{1}^{0}-\mu_{\mathrm{q}}^{0}+\mathrm{p} \mu_{\mathrm{H}^{+}}^{0}-\frac{\mathrm{p}}{2} \mu_{\mathrm{H}_{2} \mathrm{O}}^{0}}{k T}\right)=\mathrm{e}^{-\Delta \mathrm{G}^{\circ} / \mathrm{RT}}
$$

In these equations, $\mathrm{K}$ is the equilibrium constant. The subscripts 1 and q refer tomonomers $\left(\mathrm{MOO}_{4}{ }^{2-}\right)$ and q-mers $\left(\mathrm{MO}_{\mathrm{q}} \mathrm{O}_{4 \mathrm{q}-\mathrm{p} / 2}\right)$ of molybdenum, respectively. k is Boltzmann's constant, $T$ is the absolute temperature, $\Delta \mathrm{G}^{\circ}$ is the (standard) molar Gibbs free energy change, and $\mathrm{R}$ is the gas constant. If $\mathrm{K}$ is known for all species of interest $(p, q)$, then, by eq $2 \mathrm{a}$, theconcentrations of q-mers (actually $(p, q)$ mers) can be cal culated as a function of the total amount of Mo in the system (using mass conservation) and as a function of the $\mathrm{H}^{+}$concentration. This is how Figure 2 was cal culated. Hereweaim to understand theoccurrence of q-mers on the basis of thermodynamic concepts (but at the expense of details). Note that we presume here that certain cluster sizes appear. Thequestion that weaddress is, under what conditions arethese presumed cluster sizes stable? This approach is different from the approach in ref 3 , where the stable cluster sizes follow from a geometrical toy model.

Interaction Free Energy per Monomer is Approximately Constant for all Clusters. As mentioned in the Introduction, many different polyoxometalate species, or q-mers (characterized by the combination $(p, q)$ ), have been reported, and many different equilibrium constants have been proposed based on different sets of experiments. However, from themany sets of equilibrium constants that are reported in ref 2, it follows that all q-mers, toa good approximation, havethesamefreeenergy per monomer, that is,

$$
\begin{aligned}
\exp \left(\frac{\mathrm{q} \mu_{1}^{0}-\mu_{\mathrm{q}}^{0}+\mathrm{p} \mu_{\mathrm{H}^{+}}^{0}-\frac{\mathrm{p}}{2} \mu_{\mathrm{H}_{2} \mathrm{O}}^{0}}{(\mathrm{q}-1) \mathrm{kT}}\right) & = \\
\mathrm{e}^{\Delta \mathrm{G} /(\mathrm{q}-1) \mathrm{RT}}=\text { constant } &
\end{aligned}
$$

This important observation points to a single (packing) principle or rule. This is in fact the basic assumption of a recent geometrical toy model for the behavior of metal oxide clusters; see ref 3. In Table 1, we list some values of the interaction free energy per monomer using the earlier mentioned set of equilibrium constants (i.e., model G* in ref 2), but we stress that the many values of the equilibrium constants as reported in ref 2 all point to roughly the same value of the interaction free energy per monomer. Most convincingly, the values that correspond to the species whose existence has been proved $(q=7,8$, 36) also point to this same gl obal value of the interaction free energy per monomer.

It is clear from Table 1 that indeed, thereis no systematic variation of the interaction free energy per monomer, providing proof of the basic assumption in ref 3 . It also implies that only a single geometrical rule underlies the stability of metal oxide clusters. This observation is even more interesting in the light of the fact that octahedral coordination of the Mo units in the clusters is not conserved. Note that the interaction free energy is pretty large: more than 20 times the thermal energy. The constant value of theinteraction freeenergy per monomer implies that the number of bonds per monomer in the 
Table 1. Interaction Free Energies per Mo Atom in Several Clusters of Size q (Extracted from the Values of $K$ in Reference 2$)^{a}$

\begin{tabular}{rrcrlc}
\hline $\mathrm{q}$ & $\log K$ & $-\Delta \mathrm{G}^{\circ} /(\mathrm{q}-1) \mathrm{RT}$ & $\mathrm{q}$ & $\log \mathrm{K}$ & $-\Delta \mathrm{G}^{\circ} /(\mathrm{q}-1) \mathrm{RT}$ \\
\hline $7^{\mathrm{b}}$ & 52.92 & 22.7 & 18 & 185.13 & 25.1 \\
$8^{\mathrm{b}}$ & 72.59 & 24.7 & $36^{\mathrm{b}}$ & 346.5 & 22.8 \\
12 & 109.56 & 22.9 & & &
\end{tabular}

a Only nonprotonated species are listed. ${ }^{b}$ Theexistence of these clusters has been proved.

clusters is constant. Motivated by this observation, we now define

$$
\begin{aligned}
\kappa= & \mathrm{K}^{1 /(\mathrm{q}-1)}= \\
& \exp \left(\frac{-\left(\mathrm{q} \mu_{1}^{0}-\mu_{\mathrm{q}}^{0}+\mathrm{p} \mu_{\mathrm{H}^{+}}^{0}-\frac{\mathrm{p}}{2} \mu_{\mathrm{H}_{2} \mathrm{O}}^{0}\right)}{(\mathrm{q}-1) \mathrm{kT}}\right)=\mathrm{e}^{-\Delta \mathrm{G}^{\circ} /(\mathrm{q}-1) \mathrm{RT}}
\end{aligned}
$$

so that eq 2 a can be written as

$$
\mathrm{C}_{\mathrm{q}}=\kappa^{\mathrm{q}-1} \mathrm{C}_{\mathrm{H}^{+}}^{\mathrm{p}} \mathrm{C}_{1}^{\mathrm{q}}
$$

Thetotal concentration of molybdateis given by $c=\sum_{q} q c_{q}$. Defining $\mathrm{y}=\kappa \mathrm{C}, \mathrm{y}_{\mathrm{q}}=\kappa \mathrm{C}_{\mathrm{q}}$, so that $\mathrm{y}_{\mathrm{q}}=\mathrm{C}_{\mathrm{H}+}^{\mathrm{p}} \mathrm{y}_{1}^{\mathrm{q}}$, we get

$$
y=\sum_{\mathrm{q}} \mathrm{qy} \mathrm{y}_{\mathrm{q}}=\mathrm{y}_{1}+\sum_{\mathrm{q}} \mathrm{q} \mathrm{c}_{\mathrm{H}}^{\mathrm{p}}+\mathrm{y}_{1}^{\mathrm{q}}
$$

The last summation in this equation is over all clusters of sizeq $>1$, in this caseq $=7,8,12,18$, and 36 . Theabove equation only contains $y_{1}$ as the unknown variable; the concentrations of all other species, $\mathrm{y}_{\mathrm{q}}=\mathrm{c}_{\mathrm{H}^{+}}^{\mathrm{p}} \mathrm{y}_{1}^{\mathrm{q}}$, foll low from $\mathrm{y}_{1}$. We will show later that eq 5 implies that a critical concentration of monomers exists, analogous tothecritical micelle concentration in surfactant systems.

Extracting $p(q)$ from Cluster Composition. In the aboveanalysis, pand qaredependent variables: pstands for the number of protons that are consumed in order to form a cluster of size q; seethe introduction and eq 1 . We will write $p(q)$ from now on, toill ustratethat the variables $(p, q)$ are dependent . In Figure 3, we plotted $p(q)$ versus q for theonly threenonprotonated species whoseexistence has been proved: $(p, q)=(8,7),(12,8)$, and $(64,36)$. These numbers fall on a straight line given by

$$
p(q)=1.89 q-4.24
$$

The function $p(q)$ can al so be extracted from the chemical compositions of the many nonprotonated clusters as proposed (but not proved) by many sources in ref 2: from eq 1 , it follows that $p(q)$ is given by the number of oxygen atoms in a cluster, $n_{0}$, via $p=8 q-2 n_{0}$. In the inset in Figure 3 , we plotted $n_{0}$ versusq of all thepol yoxomolybdate species that were listed in ref 2; we extract p(q) and find, to a good approximation, again a linear relation given by $p(q)=1.89 q-2.73$. It turns out that this function leads to qual itatively si milar behavior as compared to eq 6; see Figure 4. However, since eq 6 is based on experimentally proved species, this is what we will use in our further calculations.

Comparison with Current Models. In Figure4a, we plotted the fraction of molybdate in clusters of size q, qcal C, as a function of $\mathrm{CH}^{+}$, for the same (total) molybdenum concentrations $(0.1 \mathrm{M})$ as in Figure 2 . These curves were calculated by numerically solving eq 5 and using eq 6 . In Figure $4 b$, as a comparison, we used $p(q)=1.89 q-2.73$ instead of eq 6, as obtained from the inset of Figure 3, based on an extensive list of polyoxomolybdate species. The different functions of $p(q)$ only lead to quantitative

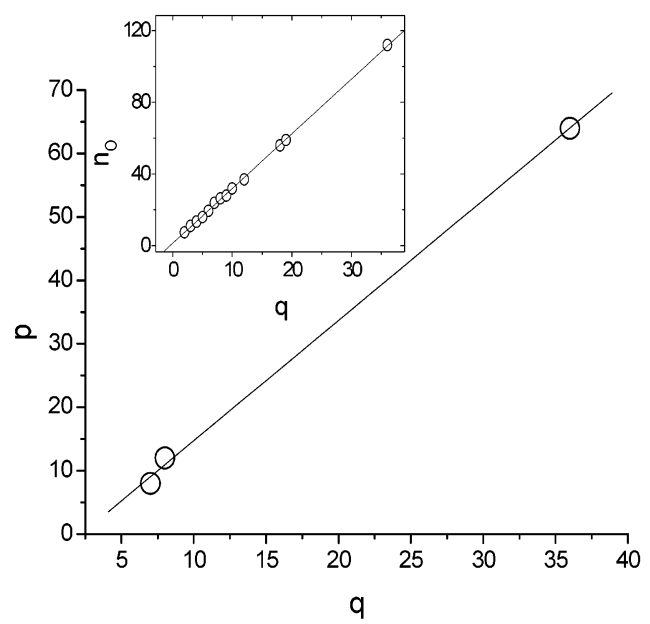

Figure 3. Plot of $p(q)$ versus $q$, wherep is the number of protons and $\mathrm{q}$ is the number of monomers that are consumed upon formation of a cluster. We pl otted the only threenonprotonated species whose existence has been proved (see description in the text). These numbers fall on a straight line given by $p(q)=$ $1.89 q-4.24$. Inset: We plot $n_{0}$ versus $q\left(n_{0}\right.$ is the number of oxygen atoms in a cluster) of all the polyoxomol ybdate species that have ever been reported, extract $p(q)$, and find, to a good approximation, a linear relation given by $p(q)=1.89 q-2.73$ (for further explanation see the text).

and no qualitative differences. As can be seen in Figure $4 a, b$, our model predicts that upon increasing the proton concentration, larger and larger species appear at the expense of smaller ones. Although this is globally in agreement with experiments, for $\mathrm{q}=8$ and $\mathrm{q}=12$ the trend is reversed compared to Figure 2: we predict that $\mathrm{q}=12$ appears at higher $\mathrm{C}_{\mathrm{H}^{+}}$than $\mathrm{q}=8$, while according to the latest reaction model, it is the other way around. As mentioned in the Introduction, however, the species $\mathrm{q}=12$ and $\mathrm{q}=18$ have never been observed directly. In particular, the proposal that $q=12$ exists is motivated by the tungsten oxide system. Indeed, strong evidence of tungsten oxideclusters containing 12 monomers has been presented; seeref 1 . M ore rel evant, thenumber of protons that the $q=12$ molybdenum species consume upon formation out of monomers seems inconsistent with the proposed equilibrium constants. Let us motivate this statement. The proposed $q=12$ molybdenum species with values of $\mathrm{p}$ between 14 and 16 (corresponding to $\mathrm{MO}_{12} \mathrm{O}_{40}(\mathrm{OH})_{2}{ }^{10-}, \mathrm{HMO}_{12} \mathrm{O}_{40}(\mathrm{OH})_{2}{ }^{9-}$, and $\mathrm{H}_{2} \mathrm{MO}_{12} \mathrm{O}_{40}(\mathrm{OH})_{2}{ }^{8-}$ ) consumesignificantly fewer protons $(\mathrm{p} / 2)$ upon formation compared to the other species: it can easily be verified that these values are between 2.4 and 4.4 smaller than expected from the behavior of the species whose existence has been proved, given by eq 6 . At the same time, its proposed equilibrium constant (shown for $(15,12)$, but the ones for $(14,12)$ and $(16,12)$ are not much different) points to an average interaction free energy that is comparable to that of the other species. However, if fewer protons are consumed, fewer bonds will be formed and thus a smaller absolute value of theinteraction freeenergy per monomer is expected. This is clearly not the case, as can be seen in Table 1. So, unless $q=12$ is stabilized by a mechanism that is completely different from that of the other species, we believethat the species $(14,12),(15,12)$, and $(16,12)$ do not exist; that is, their equilibrium constants are much smaller than those reported in ref 2 (and shown in Table 1 ), so that they are not going to appear in appreciable amounts. We do not rule out that species with $q=12$ appear, but then the corresponding $p$ value of the unprotonated species is predicted to be around $p(q=12)$ 

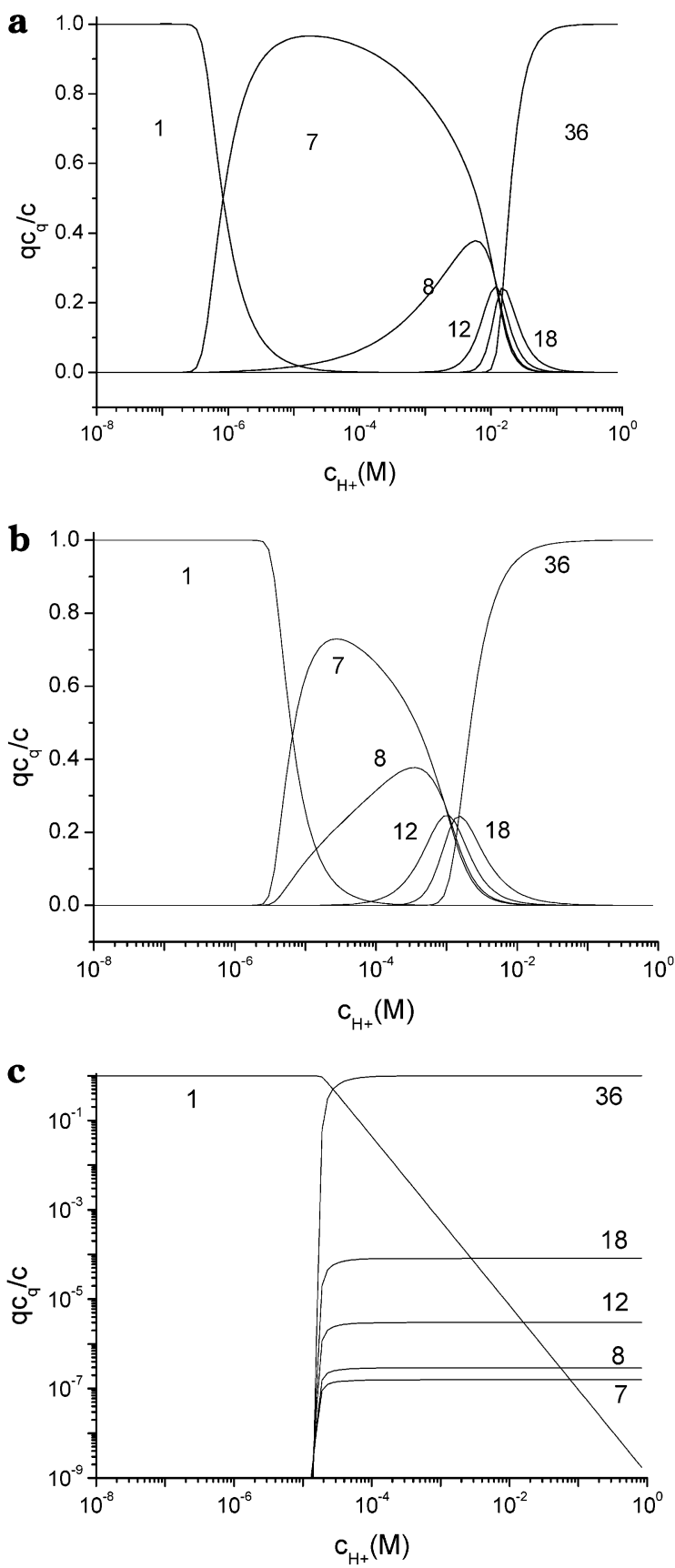

Figure 4. (a) Fraction of species of size q (indicated in the figure) as a function of the proton concentration. Thesefractions $\mathrm{q} \mathrm{c}_{\mathrm{q}} / \mathrm{c}$ were cal culated by numerically solving eq 5 with a total concentration of monomers $\mathrm{c}=0.1 \mathrm{M}, 1 / \kappa=5.43 \times 10^{-11}$, and $p(q)=1.89 q-4.24$ (eq 6) for nonprotonated species whose existence has been proved (see Figure 3). As can be seen for $q$ $=8$ and $\mathrm{q}=12$, the trend is reversed compared to Figure 2 . (b) As in panel $a$, but now for $p(q)=1.89 q-2.73$, following from an extensive list of polyoxomolybdate species that have ever been proposed; see Figure 3, inset. (c) Fraction of species $(p, q)$ as a function of proton concentration using $p(q)=1.89 q$, a total concentration of monomers $c=0.1 \mathrm{M}$, and $1 / \kappa=7.5 \times 10^{-11}$. It may seem that the species $q>1$ reach a constant value while $q=1$ keeps decreasing, thereby violating mass conservation. In fact, all cluster concentrations $q>1$ keep increasing with $\mathrm{CH}^{+}$.

$\approx 1.89 q-4.24 \approx 18$, as has implicitly been assumed in calculating Figure 4a.

The same qualitative trend as in F igure 4 is observed if $\mathrm{C}_{\mathrm{H}^{+}}$is kept constant, and the total molybdenum concentration is increased (not shown). As illustrated in Figure 4c, this behavior depends on the detailed form of the function $p(q)$. In this figure, we used $p(q)=1.89 q$, and clearly cluster fractions with $q>1$ continuously increase with proton concentration without reaching maxima. We systematically checked the influence of the function $p(q)$ on the qualitative behavior of the cluster fractions as functions of proton and total mol ybdenum concentration. We concludethat functions of the form $p(q)=a q-b$, with $a, b>0$, lead to qualitatively similar behavior as in Figure $4 a, b$. Thisillustrates that not only theinteraction energies are important (these determine if "magic numbers" such as $q=7,8,12, \ldots$ are to appear at all) but also the stoichiometry of the equilibrium qualitatively influences the behavior of the systems.

From Figure 4a,b, we cond ude that our model globally captures the behavior of the molybdate system. However, there is an important detail concerning the appearance of the species with $q=8$ and $q=12$ : our model and the reaction model in ref 2 contradict. In the next section, we will use equilibrium ultracentrifugation measurements as an attempt to settlethis issue but alsotoindependently study and check the evolution of average cluster sizes with proton concentration.

\section{Experimental Section: Equilibrium Ultracentrifugation (UC)}

Sample Preparation. Molybdenum(VI) oxide solutions were prepared at different $\mathrm{pHs}$ (adjusted by $\mathrm{HClO}_{4}$ and $\mathrm{NaOH}$ ) and at constant ionic strength of $3 \mathrm{M}^{2}$ by adding $\mathrm{NaClO}_{4}$. The total molybdate concentration in solution was $0.1 \mathrm{M}$

Determination and Calculation of Cluster Buoyant Masses. The buoyant masses of the clusters were determined from themeasured optical absorption profiles (at several wavelengths) using analytical ultracentrifugation (Beckman XL-1). If clusters do not interact, each equilibrium concentration profile (in our caseestablished after $1-2$ weeks) is an exponential function of its buoyant mass, that is,

$$
c(r)=c\left(r_{0}\right) \exp \left(\frac{m_{b} \omega^{2}\left(r^{2}-r_{0}^{2}\right)}{2 k T}\right)
$$

where $c(r)$ is the concentration as a function of radial position $r, r_{0}$ is a referenceradial position, $m_{b}$ is the buoyant mass of a single species, and $\omega$ is the rotational velocity. We expect that several different complexes are present, with sizes depending on the $\mathrm{pH}$. Concentration profiles as eq 7 in principlefollow from theoptical absorption profiles. Different clusters may absorb at different wavelengths; for this reason, the optical absorption profiles at several different wavel engths weremeasured. Thesewavelengths were chosen on the basis of the optical absorption spectra of the samples.

The buoyant mass of a cluster follows from $m_{b}=m(1$ $\left.-\rho_{\mathrm{w}} / \rho_{\mathrm{c}}\right)$, where $\mathrm{m}$ and $\rho_{\mathrm{c}}$ are the mass and mass density of a cluster, and $\rho_{\mathrm{w}}$ is the mass density of the aqueous solution. Themass densities of theclusters werecal culated from theatomicradii, assuming close packing of theatoms in a cluster. This leads to, for example, $\rho_{\mathrm{c}}=7.2 \mathrm{~g} / \mathrm{cm}^{3}$ for $\mathrm{MO}_{36} \mathrm{O}_{112^{8-}}$. To check this method of calculating mass densities, we compared the mass density as calculated above to the one reported for the crystalline form of $\mathrm{MO}_{36} \mathrm{O}_{112}\left(\mathrm{H}_{2} \mathrm{O}\right)_{16}{ }^{8-}$. The latter equals $2.77 \mathrm{~g} / \mathrm{cm}^{3} 2,4$ (note that thelargefraction of water in theclusters significantly reduces their mass density), while by our method, wefind

(4) Tytko, K.-H.; Schonfeld, B.; Buss, B.; Glemser, O. Angew. Chem. $1973,85,305$. 


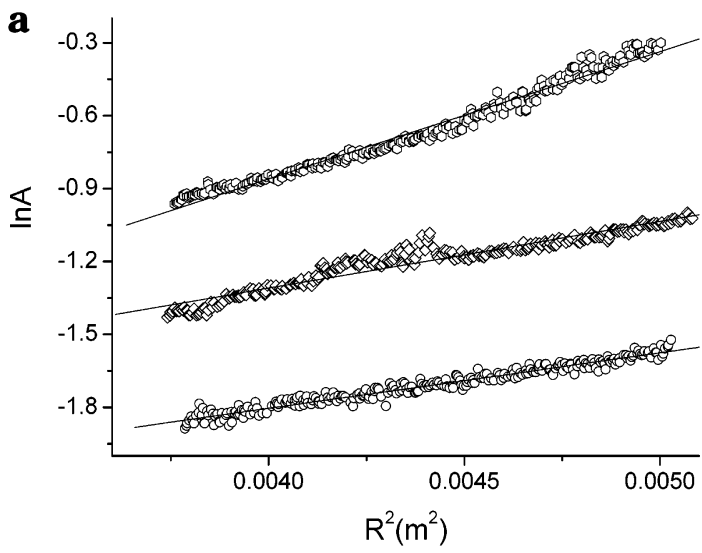

b

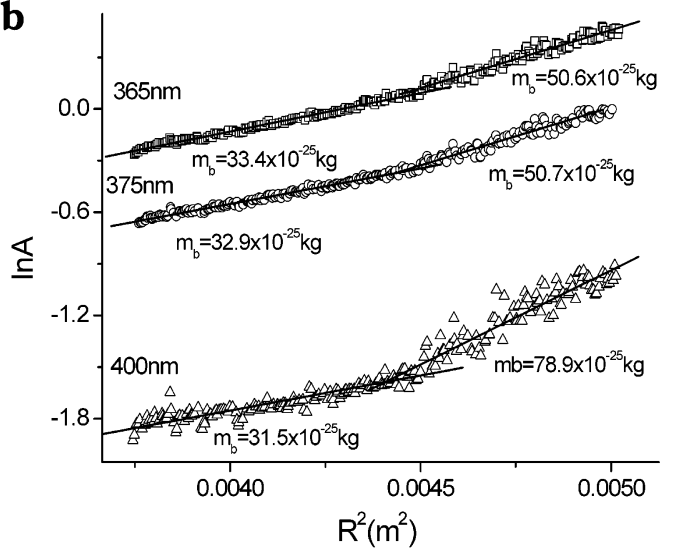

Figure 5. (a) Representative equilibrium optical absorption profiles of systems with different $\mathrm{pH}$ values and constant total molybdate concentration ( $0.1 \mathrm{M} \mathrm{Mo})$, in an ultracentrifuge $(\omega$ $=10^{4} \mathrm{rpm}$ ), plotted as In A versus $r^{2}$ (see eq 7 and the discussion in the Experimental Section). The buoyant masses, $m_{b}$, of the clusters that follow from the slopes of the curves are $m_{b}=17.0$ $\times 10^{-25} \mathrm{~kg}(\mathrm{pH}=6,360 \mathrm{~nm}, 0), \mathrm{m}_{\mathrm{b}}=20.4 \times 10^{-25} \mathrm{~kg}(\mathrm{pH}=$ $4,380 \mathrm{~nm}, \square)$, and $\mathrm{m}_{\mathrm{b}}=39.2 \times 10^{-25} \mathrm{~kg}(\mathrm{pH}=2,375 \mathrm{~nm}, 0)$. (b) As in panel a, but only for the system at $\mathrm{pH}=2$, observed at different wavelengths, indicated in the figure. The curves clearly consist of two linear parts. The buoyant masses, $m_{b}$, of the particles that follow from the slopes of the curves are indicated in the figure. The curves are noisy due to very small absorption at the observed wavelength. However, the buoyant masses cal culated from the largest slopes indicatethe presence of clusters with $q=64$; for more details see the Experimental Section.

a value of $3.55 \mathrm{~g} / \mathrm{cm}^{3}$ for $\mathrm{M} \mathrm{O}_{36} \mathrm{O}_{112}\left(\mathrm{H}_{2} \mathrm{O}\right)_{16}{ }^{8-}$. This is an acceptable difference, in particular considering the fact that throughout the crystals of $\mathrm{M}_{36} \mathrm{O}_{112}\left(\mathrm{H}_{2} \mathrm{O}\right)_{16}{ }^{8-}$, atoms arenot close-packed. Notethat even though theerror that wemakein calculating $\rho_{c}$ is significant, theer ror it causes in $m_{b}$ is still small as long as $\rho_{\mathrm{w}} / \rho_{\mathrm{c}} \ll 1$, which is the case here. Thus we estimate the error we make in calculating the buoyant masses to be less than $10 \%$.

Experimental Results. It can immediately be seen in Figure 5a, where we plotted (the logarithm of) the absorption profile, that clusters becomelarger, on average, upon decreasing the $\mathrm{pH}$. At the smallest investigated $\mathrm{pH}$ value of 2, two linear parts of the profiles can be distinguished, as shown in Figure 5b. We believe that these two parts indicate the presence of two significantly different cluster sizes. Thebuoyant masses extracted from the absorption profiles slightly depend on the wavel ength at which they were measured. In Table 2, we summarize the results. Table $2 a$ contains the cal culated values of an extensive list of complexes at the pHs where they are expected, based on ref 2 . Table $2 \mathrm{~b}$ lists theexperimentally observed buoyant masses, at different $\mathrm{pHs}$ and wave
Table 2

(a) Proposed Clusters and Their Calculated Buoyant Masses $\left(m_{b}\right)$ at Several $\mathrm{pH}$ Values

\begin{tabular}{|c|c|c|c|}
\hline $\mathrm{pH}$ & $(p, q)$ & complexes & $\begin{array}{c}\mathrm{m}_{\mathrm{b}}\left(\times 10^{-25}\right) \mathrm{kg} \\
\quad(\text { calculated })\end{array}$ \\
\hline 6 & $(8,7)$ & $\mathrm{MO}_{7} \mathrm{O}_{24}{ }^{6-}$ & 14.9 \\
\hline 6 & $(8,7)$ & $\mathrm{Mo}_{7} \mathrm{O}_{20}(\mathrm{OH})_{8}^{6-}$ & 16.6 \\
\hline 6 & $(9,7)$ & $\mathrm{HMO}_{7} \mathrm{O}_{24}{ }^{--}$ & 15.0 \\
\hline 6 & $(14,12)$ & $\mathrm{MO}_{12} \mathrm{O}_{40}(\mathrm{OH})_{2}{ }^{10-}$ & 26.0 \\
\hline 4 & $(8,7)$ & $\mathrm{Mo}_{7} \mathrm{O}_{24}{ }^{6-}$ & 14.9 \\
\hline 4 & $(8,7)$ & $\mathrm{Mo}_{7} \mathrm{O}_{20}(\mathrm{OH})_{8}^{6-}$ & 16.6 \\
\hline 4 & $(9,7)$ & $\mathrm{HMO}_{7} \mathrm{O}_{24}{ }^{--}$ & 15.0 \\
\hline 4 & $(10,7)$ & $\mathrm{H}_{2} \mathrm{Mo}_{7} \mathrm{O}_{24}{ }^{4-}$ & 15.0 \\
\hline 4 & $(12,8)$ & $\mathrm{MO}_{8} \mathrm{O}_{26}{ }^{4-}$ & 16.8 \\
\hline 4 & $(15,12)$ & $\mathrm{HMO}_{12} \mathrm{O}_{40}(\mathrm{OH})_{2}{ }^{9-}$ & 26.0 \\
\hline 4 & $(16,12)$ & $\mathrm{H}_{2} \mathrm{MO}_{12} \mathrm{O}_{40}(\mathrm{OH})_{2}{ }^{8-}$ & 26.0 \\
\hline 2 & $(10,7)$ & $\mathrm{H}_{2} \mathrm{Mo}_{7} \mathrm{O}_{24}{ }^{4-}$ & 15.0 \\
\hline 2 & $(12,8)$ & $\mathrm{MO}_{8} \mathrm{O}_{26} 4^{4-}$ & 16.9 \\
\hline 2 & $(11,7)$ & $\mathrm{H}_{3} \mathrm{MO}_{7} \mathrm{O}_{24}{ }^{3-}$ & 15.0 \\
\hline 2 & $(13,8)$ & $\mathrm{HMO}_{8} \mathrm{O}_{26}{ }^{3-}$ & 16.9 \\
\hline 2 & $(32,18)$ & $\mathrm{MO}_{18} \mathrm{O}_{56}{ }^{4-}$ & 37.5 \\
\hline 2 & $(32,18)$ & $\mathrm{MO}_{18} \mathrm{O}_{56}\left(\mathrm{H}_{2} \mathrm{O}\right)_{10}{ }^{4-}$ & 31.9 \\
\hline 2 & $(32,18)$ & $\mathrm{MO}_{18} \mathrm{O}_{54}(\mathrm{OH})_{4}\left(\mathrm{H}_{2} \mathrm{O}\right)_{8}^{4-}$ & 33.8 \\
\hline 2 & $(64,36)$ & $\mathrm{Mo}_{36} \mathrm{O}_{112^{8-}}$ & 75.0 \\
\hline 2 & $(64,36)$ & $\mathrm{MO}_{36} \mathrm{O}_{112}\left(\mathrm{H}_{2} \mathrm{O}\right)_{16^{8-}}$ & 66.1 \\
\hline 1 & $(2,1)$ & & \\
\hline 1 & $(5,2)$ & & \\
\hline 1 & $(32,18)$ & $\mathrm{MO}_{18} \mathrm{O}_{56}{ }^{4-}$ & 37.5 \\
\hline 1 & $(32,18)$ & $\mathrm{MO}_{18} \mathrm{O}_{56}\left(\mathrm{H}_{2} \mathrm{O}\right)_{10^{4-}}$ & 31.9 \\
\hline 1 & $(32,18)$ & $\mathrm{MO}_{18} \mathrm{O}_{54}(\mathrm{OH})_{4}\left(\mathrm{H}_{2} \mathrm{O}\right)_{8}^{4-}$ & 33.8 \\
\hline 1 & $(64,36)$ & $\mathrm{MO}_{36} \mathrm{O}_{112}{ }^{8-}$ & 75.0 \\
\hline 1 & $(64,36)$ & $\mathrm{MO}_{36} \mathrm{O}_{112}\left(\mathrm{H}_{2} \mathrm{O}\right)_{16^{8-}}$ & 66.1 \\
\hline
\end{tabular}

(b) Buoyant Masses $\left(m_{b}\right)$ at Different $\mathrm{pH}$ Values, Observed at Different Wavelengths $\lambda$

\begin{tabular}{cccccc}
\hline $\mathrm{pH}$ & $\begin{array}{c}\mathrm{m}_{\mathrm{b}}\left(\times 10^{-25} \mathrm{~kg}\right) \\
(\mathrm{UC})\end{array}$ & $\begin{array}{c}\lambda \\
(\mathrm{nm})\end{array}$ & $\mathrm{pH}$ & $\begin{array}{c}\mathrm{m}_{\mathrm{b}}\left(\times 10^{-25} \mathrm{~kg}\right) \\
(\mathrm{UC})\end{array}$ & $\begin{array}{c}\lambda \\
(\mathrm{nm})\end{array}$ \\
\hline 6 & 15.0 & 345 & 2 & 42.2 & 365 \\
6 & 15.5 & 350 & 2 & 32.0 & 370 \\
6 & 17.0 & 360 & 2 & 39.2 & 375 \\
6 & 18.0 & 370 & 2 & 41.0 & 400 \\
4 & 19.3 & 360 & 2 & $(33.4)$ & 365 \\
4 & 19.4 & 365 & 2 & $(32.9)$ & 375 \\
4 & 19.7 & 370 & 2 & $(31.5)$ & 400 \\
4 & 20.4 & 380 & 2 & $(50.6)$ & 365 \\
4 & 21.1 & 390 & 2 & $(78.9)$ & 400
\end{tabular}

lengths. The values between brackets wereextracted from profiles corresponding to (at least) two differently sized clusters, shown in detail in Figure $5 b$.

As far as weare aware, only the cluster with $q=36$ has been observed by UC measurements. ${ }^{4}$ Comparing sections $\mathrm{a}$ and $\mathrm{b}$ of Table 2 verifies the presence of $\mathrm{q}=7$ and $\mathrm{q}=$ 8 at $\mathrm{pH}=6$ and $\mathrm{pH}=4$, as well as $\mathrm{q}=18$ and $\mathrm{q}=36$ at $\mathrm{pH}=2$. The value of $\mathrm{m}_{\mathrm{b}} \approx 50 \times 10^{-25} \mathrm{~kg}$, as extracted from the steepest part of absorption profiles (not the average) shown in Figure $5 b$, does not correspond to any of the proposed clusters in Table 2a. Probably this value does not correspond to a single species but arises because of the presence of both $q=18$ and $q=36$ clusters. Indeed, the profile at larger wavelength clearly points to $q=18$ and $\mathrm{q}=36$ being present. It is expected that the largest cluster absorbs at larger wavelength than the smallest cluster, and therefore the profile at larger wavelength is more sensitive to $q=36$.

The value of $m_{b}$ that we find that is the closest to $a$ cluster with $\mathrm{q}=12$ is $21 \times 10^{-25} \mathrm{~kg}$ at $\mathrm{pH}=4$. However, this value is still cl oser to a cluster with $q=8$; see Table $2 a$. There is no indication that the sedimentation profiles at $\mathrm{pH}=4$ consist of two parts, as in Figure $5 \mathrm{~b}$. Therefore, it is not plausible that the value of $\mathrm{m}_{\mathrm{b}} \approx 21 \times 10^{-25} \mathrm{~kg}$ is effectively an average between clusters of different sizes, although it cannot be ruled out at this point. From the 
data presented here, weareled to believethat $q=12$ does not show up in detectable concentrations in the samples that we studied. However, $q=18$ has, to our knowledge, never been observed before; it has been proposed by symmetry considerations. ${ }^{2}$ Wefind strong indications that this cluster with $\mathrm{q}=18$ is indeed stable at $\mathrm{pH}=2$. It clearly follows from Table $2 \mathrm{~b}$ that clusters become larger on average upon decreasing the $\mathrm{pH}$, as predicted.

\section{Connection with Micelle Formation}

If $\mathrm{CH}^{+}$is set to unity and if only a single species with $\mathrm{q}$ $>1$ is present, then eq 5 reduces to the well-known equation by Debye ${ }^{5}$ that describes micelleformation: $y=$ $\mathrm{y}_{1}+q \mathrm{y}_{1}^{\mathrm{q}}$. In that case, $\mathrm{y}_{1}$ corresponds to surfactant monomers, and $y_{q}=y_{1}^{q}$ to micelles of sizeq; a typical value of q would be 80 in micelles. ${ }^{6}$ Regardingthetotal surfactant concentration $y$ as the variable, $y_{1}=y$ as long as $y<1$ and $q \gg 1$. In other words, as long as the total concentration of surfactants is small, only monomers appear. As soon as y becomes of order unity, however, the second term takes over: $y_{1}$ becomes unity and almost constant while the concentration of monomers in the form of clusters, qy $y_{a}$ $=\mathrm{qy}_{1}^{\mathrm{q}}$, increases linearly with $\mathrm{y}$. At thecrossover, from the definition $\mathrm{y}=\kappa \mathrm{C}$ and $\mathrm{y}_{\mathrm{q}}=\kappa \mathrm{C}_{\mathrm{q}}$ it is easy to see that the real concentration of monomers $C_{1}=1 / \kappa$. This well-known quantity is the critical micel le concentration.

In the case of cluster formation in metal oxides, the situation is a little more complicated but not fundamentally different from the situation described above. First of all, if $\mathrm{C}_{\mathrm{H}^{+}}=1$, the limiting concentration of cluster monomers is indeed $\mathrm{y}_{1} \approx 1$ or $\mathrm{C}_{1} \approx 1 / \kappa$. This is shown in Figure 6 where we plotted the monomer concentration $\mathrm{y}_{1}$ versus $y$. Since $q$ is not very much larger than unity (the smallest value that we have is $q=7$ ), the crossover from $\mathrm{y}_{1}=\mathrm{y}$ to $\mathrm{y}_{1} \approx 1$ that we observe is not as sharp as it is for micelles where $q \gg 1$. At other proton concentrations, the critical value of $y$ above which clusters start forming depends on the proton concentration and on the value of q corresponding to the cluster first formed, $q^{\prime}$. We propose toterm this value of $\mathrm{y}_{1}$ the "critical cluster concentration". Indeed, the value of the critical cluster concentration follows from $\mathrm{y}_{1} \approx \mathrm{y}_{\mathrm{q}}=\mathrm{c}_{\mathrm{H}^{+}}^{\mathrm{p}\left(\mathrm{q}^{\prime}\right)} \mathrm{y}_{1}^{\mathrm{q}^{\prime}}$ and is given by

$$
y_{1}^{*}=c_{H^{+}}^{-p\left(q^{\prime}\right) /\left(q^{\prime}-1\right)}
$$

or in terms of the real monomer concentration

$$
\mathrm{C}_{1}^{*}=\kappa^{-1} \mathrm{C}_{\mathrm{H}^{+}}^{-\mathrm{p}\left(\mathrm{q}^{\prime}\right) /\left(\mathrm{q}^{\prime}-1\right)}
$$

where the star indicates the value of the critical cluster concentration. It can beverified from Figure 6 that indeed,

(5) Debye, P. J . W. Ann. N.Y. Acad. Sci. 1949, 51, 575.

(6) Israelachvili, J. Intermolecular \& Surface Forces, 2nd ed.; Academic Press: San Diego, 1992.

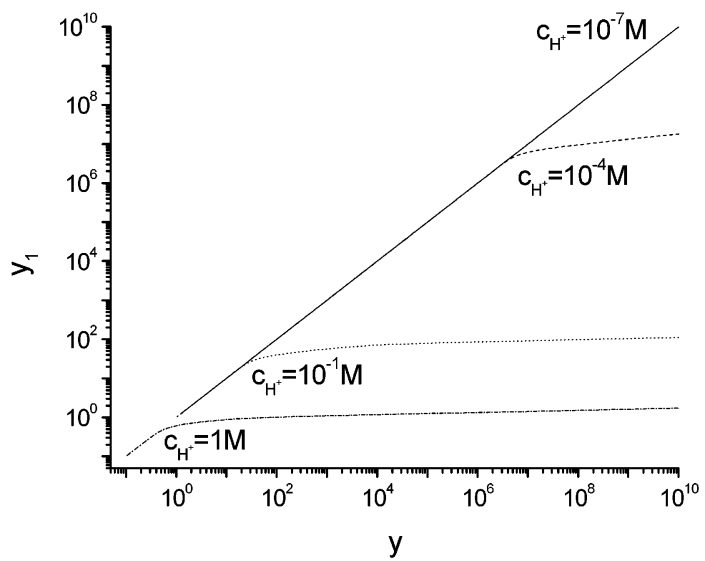

Figure 6. Concentration of free monomers $y_{1}$, as a function of the total monomer concentration, $y$, at several values of the proton concentration indicated in the figure. Curves are plots of the function $y=\sum_{q} q y_{q}$ (eq 5). The crossovers from $y_{1}$ rising linearly with y to almost constant values indicate cluster formation analogous to the formation of micelles in surfactant solutions (see explanation in the text).

these values of $y_{1}^{*}$ or $c_{1}^{*}$ as a function of proton concentration are well described by eq 8.

\section{Concluding Remarks}

Wehaveshown that the conditions under which clusters of molybdenum oxide are stable follow from two basic assumptions: (1) the average interaction free energy per monomer in a cluster is constant and independent of cluster sizeq, and (2) the relation between the number of protons required to form a cluster of size $q, p(q)$, is a function of $q$ of the form $p(q)=a q-b$, with $a, b>0$. Using theseconsiderations as input in a phenomenol ogical model, we predict, among other things, that clusters of increasing sizeappear upon increasing the proton concentration. This is gl obally in agreement with experiments, but in current reaction model $s^{2}$ the situation for clusters containing 8 and $12 \mathrm{Mo}$ atoms is reversed with respect to our predictions. Using ultracentrifugation measurements, wefound no indications that clusters with 12 Mo atoms exist at all, which resolves the controversy. We do find indications for the presence of another species not seen before: clusters containing $18 \mathrm{Mo}$ atoms.

Finally, weshowed that globally, molybdenum(VI) oxide clusters behave as micelles. However, the critical cluster concentration sensitively depends on proton concentration and is given by eq 8 . Our next goal is to generalize the concepts provided in this work to the beautiful, highly symmetrical clusters with reduced centers $(\mathrm{Mo}(\mathrm{V}))$ containing up to 176 monomers or the ones found in the presence of acetate and sulfate ions that may contain as many as 132 and 368 monomers, respectively; see, for example, refs 7 and 8.

\section{LA035986F}

(7) Müller, A.; Krickemeyer, E.; Dillinger, S.; Bogge, H.; Proust, A.; Plass, W.; Rohlfing, R. Naturwissenschaften 1993, 80, 560.

(8) Müller, A.; Kögerler, P.; Bögge, H. Struct. Bonding 2000, 96, 203. 